\title{
Automated and sensitive determination of four anabolic androgenic steroids in urine by online turbulent flow solid-phase extraction coupled with liquid chromatography-tandem mass spectrometry: A novel approach for clinical monitoring and doping control
}

\author{
Feng Guo $^{a}$, Jing Shao ${ }^{b}$, Qian Liu ${ }^{\text {a }}$, Jian-bo Shi ${ }^{\text {a,* }}$, Gui-bin Jiang ${ }^{\text {a }}$ \\ a State Key Laboratory of Environmental Chemistry and Ecotoxicology, Research Center for Eco-Environmental Sciences, \\ Chinese Academy of Sciences, Beijing 100085, China \\ ${ }^{\mathrm{b}}$ National Institute of Sports Medicine, Beijing 100029, China
}

\section{A R T I C L E I N F O}

\section{Article history:}

Received 30 December 2013

Received in revised form

2 March 2014

Accepted 10 March 2014

Available online 14 March 2014

Keywords:

Online turboflow solid-phase extraction

Anabolic androgenic steroids

Urine

Clinical monitoring

Doping control

\begin{abstract}
A B S T R A C T
A novel method for automated and sensitive analysis of testosterone, androstenedione, methyltestosterone and methenolone in urine samples by online turbulent flow solid-phase extraction coupled with high performance liquid chromatography-tandem mass spectrometry was developed. The optimization and validation of the method were discussed in detail. The Turboflow C18-P SPE column showed the best extraction efficiency for all the analytes. Nanogram per liter ( $\mathrm{ng} / \mathrm{L}$ ) level of AAS could be determined directly and the limits of quantification (LOQs) were $0.01 \mathrm{ng} / \mathrm{mL}$, which were much lower than normally concerned concentrations for these typical anabolic androgenic steroids (AAS) $(0.1 \mathrm{ng} / \mathrm{mL})$. The linearity range was from the LOQ to $100 \mathrm{ng} / \mathrm{mL}$ for each compound, with the coefficients of determination $\left(r^{2}\right)$ ranging from 0.9990 to 0.9999 . The intraday and interday relative standard deviations (RSDs) ranged from $1.1 \%$ to $14.5 \%(n=5)$. The proposed method was successfully applied to the analysis of urine samples collected from 24 male athletes and 15 patients of prostate cancer. The proposed method provides an alternative practical way to rapidly determine AAS in urine samples, especially for clinical monitoring and doping control.
\end{abstract}

(c) 2014 Elsevier B.V. All rights reserved.

\section{Introduction}

Anabolic androgenic steroids (AAS) are synthetic derivatives of testosterone originally designed for therapeutic uses to provide enhanced anabolic potency with negligible androgenic effect $[1,2]$. These substances promote the growth of skeletal muscle and the development of male sexual characteristics. They are naturally produced in the testicles and adrenal glands and can also be synthetically created. Testosterone is one of the predominant endogenous anabolic androgenic steroids [3]. It has anabolic effects, causing muscle and bone growth and maturation. Androstenedione is the most common precursor of sex hormones [4]. It works by increasing the amount of androstenedione which in turn increases the amount of testosterone in the body [4,5]. Exogenous anabolic androgenic steroids which have more anabolic and less androgenic activity than testosterone are synthesized and

\footnotetext{
* Corresponding author. Tel./fax: +861062849129.

E-mail address: jbshi@rcees.ac.cn (J.-b. Shi).
}

used therapeutically in medicine. Methyltestosterone is the first synthetic anabolic steroids and its importance of therapeutic use was recognized in the 1950s [6]. Since then, a large amount of anabolic steroids are synthesized and tested.

Both endogenous and exogenous AAS continue to be used clinically today to treat conditions resulting from steroid hormone deficiency, such as delayed puberty, as well as diseases that result in loss of lean muscle mass, such as cancer and AIDS [7]. However, long term usage of anabolic steroids can cause many adverse effects such as gynecomastia, elevated blood pressure, liver damage, cardiovascular disease or coronary artery disease. Serum concentrations of AAS are of particular importance and often monitored for diagnosis, treatment or research on the relationship between their concentrations and diseases [8-11]. Urinary concentrations are also received great attention because of its noninvasive detection [12-14]. Furthermore, AAS are even misused by athletes to improve their sports performance $[6,15]$. Although the use of AAS has been banned in sports and governed by the World Anti-Doping Agency since 1976, some of the priority controlled substances such as methenolone were still detected in urine at the 
London Olympic Games in 2012 [16] and the National Basketball Association Championship (USA) in 2013 [17], which are regulated as "Zero detection" in the games.

Some analytical methods have been used to analyze anabolic androgenic steroids, including Immunoassay [18], GC-MS/MS $[19,20]$ and LC-MS/MS [21-23]. Immunoassay is a feasible method in the clinical laboratory but it is susceptible to matrix interference especially for determination of low concentration. The specificity also limits its application for simultaneous detection of a number of analytes. GC-MS/MS is widely used due to its high sensitivity and selectivity, but the derivatization procedure is complicated and sometimes the derivative efficiency is low. LC-MS/MS with relative simpler pretreatment, good sensitivity and selectivity receives analysts' favor especially in the analysis of low levels of AAS in biological samples [24]. The traditional pretreatment procedures, such as liquid-liquid extraction and off-line solid phase extraction, are not only time-consuming but also solvent and labor cost. Meanwhile, the operative error is hard to be avoided. In order to simplify the pretreatment procedure and improve the method sensitivity, some new techniques such as molecular imprinted polymer solid phase extraction (SPE) $[25,26]$, solid phase microextraction (SPME) [27], stir bar microextraction (SBME) [28] and online SPE [29,30], have also been applied to determine AAS in diverse biological samples.

In this work, an automated and sensitive method for detecting testosterone, androstenedione, methyltestosterone and methenolone in urine by online turbulent flow solid-phase extraction coupled with liquid chromatography-tandem mass spectrometry (TF-SPE-HPLC-MS/MS) was developed. The development, validation and implementation of the method were discussed in detail. The LOQs were 10-100 times lower than the reported method, and the nanogram per liter (ng/L) level of AAS could be determined directly with large volume injection of $1.0 \mathrm{~mL}$ urine samples. The proposed method was successfully used to analyze 39 urine samples including 24 ones from male athletes and 15 ones from patients of prostate cancer.

\section{Experimental}

\subsection{Chemicals and materials}

Standards for testosterone (T), androstenedione (ADD), methyltestosterone (MTT), were purchased from Dr. Ehrenstorfer $\mathrm{GmbH}$, Germany. Methenolone (MET) was purchased from Sigma-Aldrich, USA. Their molecular structures are shown in Table 1. Stock solutions $(1 \mathrm{mg} / \mathrm{mL})$ were prepared by dissolving $10 \mathrm{mg}$ of each standard in $10 \mathrm{~mL}$ of methanol and stored at $4{ }^{\circ} \mathrm{C}$. Working solutions were prepared by diluting the stock solutions with water. HPLC grade Acetonitrile was purchased from J.T. Baker (Phillipsburg, NJ). HPLC grade formic acid was purchased from Dikma Technology Inc., USA. Ultrapure water was produced with a Milli-Q system (Millipore, Billerica, MA). All reagents were of analytical grade unless otherwise noted.

\subsection{Instrumentation}

The UltiMate 3000 system (Thermo, USA) consisted of a WPS-3000TSL autosampler with large-volume loop $(2.5 \mathrm{~mL})$ for injection. A TCC-3200 thermostated column compartment with a two-position, six-port (2P-6P) valve, a DGP 3600M dual-gradient pump, and a SRD 3600 solvent rack with integrated vacuum degasser were included. The whole system was controlled by Chromeleon ${ }^{\mathbb{R}}$ Chromatography Management Software (v. 6.80, Dionex, USA). A Quattro Ultima triple quadrupole mass spectrometer (Premier XE, Waters, USA) equipped with an electron spray ionization (ESI) source (Waters, USA) was used for measuring target compounds. The data were recorded by Masslynx 4.1 software.

Table 1

The molecular structures of the four AAS and their MRM parameters for tandem mass spectrometry.

\begin{tabular}{|c|c|c|c|c|c|c|}
\hline Compounds & MRM transitions $(m / z)$ & Dwell time (s) & Cone (V) & Collision (V) & Ion mode & Molecular structures \\
\hline ADD & $\begin{array}{l}287>97 \\
287>109\end{array}$ & 0.1 & $\begin{array}{l}30 \\
30\end{array}$ & $\begin{array}{l}20 \\
20\end{array}$ & PI & \\
\hline $\mathrm{T}$ & $\begin{array}{l}289>97 \\
289>109\end{array}$ & 0.1 & $\begin{array}{l}40 \\
40\end{array}$ & $\begin{array}{l}25 \\
25\end{array}$ & PI & \\
\hline MTT & $\begin{array}{l}303>97 \\
303>109\end{array}$ & 0.1 & $\begin{array}{l}40 \\
40\end{array}$ & $\begin{array}{l}35 \\
35\end{array}$ & PI & \\
\hline MET & $\begin{array}{l}303.4>82.9 \\
303.4>187\end{array}$ & 0.1 & $\begin{array}{l}35 \\
35\end{array}$ & $\begin{array}{l}20 \\
20\end{array}$ & PI & \\
\hline
\end{tabular}


The schematic setup of the online TF-SPE-HPLC-MS/MS system is shown in Fig. 1.

\subsection{Online SPE procedure}

For online SPE procedure, sample preconcentration, cleanup, and SPE column regeneration were included. The mobile phase consisted of $(A)$ formic acid solution $(0.1 \%, v / v)$ and $(B)$ acetonitrile (ACN) for both pumps. Each $1.0 \mathrm{~mL}$ sample was drawn by syringe from a $1.5 \mathrm{~mL}$ vial and pumped into the large-volume loop, which was carried over by the mobile phase from pump 1 (loading pump) and then delivered to the online SPE column (Turboflow C18-P, $60 \mu \mathrm{m}, 1.0 \times 50 \mathrm{~mm}$, Thermo Scientific) with a high flow rate of mobile phase ( $4 \mathrm{~mL} / \mathrm{min}, 5 \% \mathrm{ACN}$ ) for pump 1 . After sample loading, the cleanup step began. Keeping the mobile phase $(4 \mathrm{~mL} / \mathrm{min}$, $5 \% \mathrm{ACN}$ ) for $1.0 \mathrm{~min}$ was enough to remove matrix components concentrated on the SPE column. In order to remove any residual contamination and ensure method reproducibility, the SPE column was needed to be regenerated after elution step. The result showed flushing with 95\% ACN for 13 min was enough for this. Finally, the mobile phase was returned to the original condition for the next step. The online SPE procedure for pump 1 and the schedules of valve switching are listed in Table 2.

\subsection{HPLC analysis}

After cleanup step, the valve was switched to elute the analytes from the SPE column to the analytical column in back-flush mode and kept for $1.0 \mathrm{~min}$. Then the valve was transferred back and the eluted analytes were further separated on an analytical column (Acclaim ${ }^{\circledR}$ PA2, $3 \mu \mathrm{m}, 3.0 \times 150 \mathrm{~mm}$, Thermo Scientific). The analytical column temperature was $40^{\circ} \mathrm{C}$. The gradient elution and separation condition for pump 2 are listed in Table 2 .

\subsection{Sample collection and preparation}

A total of 39 urine samples were collected. Twenty four samples were collected from 24 male athletes. Another 15 samples were collected from patients of prostate cancer in a hospital. The samples were kept in clean plastic bottles at $-20^{\circ} \mathrm{C}$, and thawed at $4{ }^{\circ} \mathrm{C}$ before using. All the samples were centrifuged $(12,000 \mathrm{r} / \mathrm{min}$, $10 \mathrm{~min}$ ) before analysis.

\section{Results and discussion}

\subsection{Optimization of mass spectrometry}

For optimization of mass spectrometric parameters, testosterone was chosen as the representative chemical. Capillary voltage, source temperature, desolvation temperature, cone gas flow and desolvation gas flow were optimized beforehand. The other three analytes were further optimized starting from the confirmed conditions of testosterone. Each standard solution was diluted with methanol and all the concentrations of AAS were $1000 \mathrm{ng} / \mathrm{mL}$. Standard solutions of $5 \mu \mathrm{L}$ were infused at $10 \mu \mathrm{L} / \mathrm{min}$ and carried by the mobile phase ( $50 \%$ acetonitrile and $50 \% \mathrm{H}_{2} \mathrm{O}, 0.5 \mathrm{~mL} / \mathrm{min}$ ) into the mass spectrometer. The cone voltage and collision energy were particularly optimized for each analyte from $10 \mathrm{~V}$ to $60 \mathrm{~V}$ respectively. The final results of cone voltage and collision energy are shown in Table 1. The other optimized ESI source conditions were capillary voltage $3 \mathrm{kV}$; source temperature $110{ }^{\circ} \mathrm{C}$; desolvation temperature $450{ }^{\circ} \mathrm{C}$; cone gas flow $50 \mathrm{~L} / \mathrm{h}$ and desolvation gas flow $450 \mathrm{~L} / \mathrm{h}$. Formic acid $(0.1 \%, \mathrm{v} / \mathrm{v})$ solution was used as a

Table 2

Online SPE procedure, HPLC gradient elution and valve switching program.

\begin{tabular}{|c|c|c|c|c|c|c|c|}
\hline \multirow[t]{2}{*}{ Time (min) } & \multicolumn{3}{|c|}{ Pump 1} & \multicolumn{3}{|c|}{ Pump 2} & \multirow{2}{*}{$\begin{array}{l}\text { Valve } \\
\text { position }\end{array}$} \\
\hline & A (\%) & B (\%) & $\begin{array}{l}\text { Flow rate } \\
(\mathrm{mL} / \mathrm{min})\end{array}$ & A (\%) & B (\%) & $\begin{array}{l}\text { Flow rate } \\
(\mathrm{mL} / \mathrm{min})\end{array}$ & \\
\hline-0.5 & 95 & 5 & 4.0 & 60 & 40 & 0.2 & Load \\
\hline 0.0 & 95 & 5 & 4.0 & 60 & 40 & 0.2 & Load \\
\hline 1.0 & 95 & 5 & 4.0 & 60 & 40 & 0.2 & Load \\
\hline 1.1 & 95 & 5 & 1.0 & 60 & 40 & 0.2 & Inject \\
\hline 2.1 & 95 & 5 & 1.0 & 60 & 40 & 0.2 & Load \\
\hline 7.0 & 5 & 95 & 1.0 & 60 & 40 & 0.2 & Load \\
\hline 12.0 & 5 & 95 & 1.0 & 40 & 60 & 0.2 & Load \\
\hline 20.5 & 5 & 95 & 1.0 & 5 & 95 & 0.2 & Load \\
\hline 20.6 & 95 & 5 & 4.0 & 5 & 95 & 0.2 & Load \\
\hline 22.0 & 95 & 5 & 4.0 & 0 & 100 & 0.2 & Load \\
\hline 27.0 & 95 & 5 & 4.0 & 0 & 100 & 0.2 & Load \\
\hline 27.1 & 95 & 5 & 4.0 & 60 & 40 & 0.2 & Load \\
\hline 32.0 & 95 & 5 & 4.0 & 60 & 40 & 0.2 & Load \\
\hline
\end{tabular}

“ -0.5 " stands for sample loading time before the start time of baseline acquisition (recorded as "0"). Mobile phase: A, Formic acid solution $(0.1 \%, v / v)$; B, ACN.

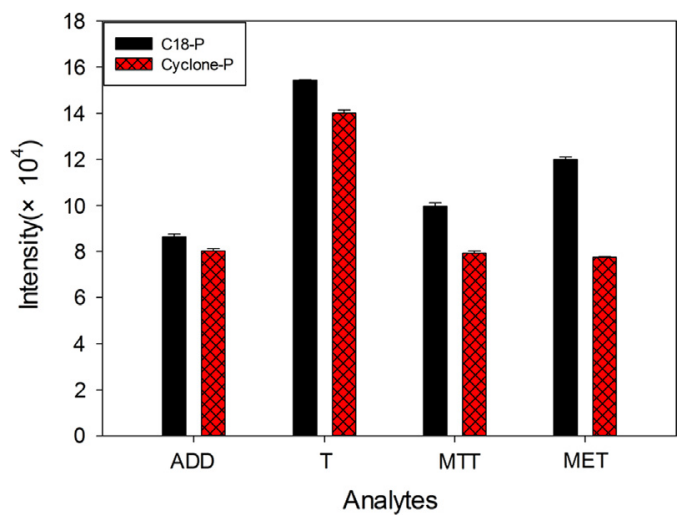

Fig. 2. The extraction efficiencies and relative standard deviations when using Turboflow C18-P column $(60 \mu \mathrm{m}, 1.0 \times 50 \mathrm{~mm})$ and Turboflow Cyclone-P column $(60 \mu \mathrm{m}, 1.0 \times 50 \mathrm{~mm})$. The spiked $40 \mathrm{ng} / \mathrm{mL}$ standard solutions was run in replicate $(n=5)$. Sample volume $100 \mu \mathrm{L}$. Sample cleanup with $5 \%$ ACN (v/v) for $1 \mathrm{~min}$. Sample loading flow rate $2 \mathrm{~mL} / \mathrm{min}$.

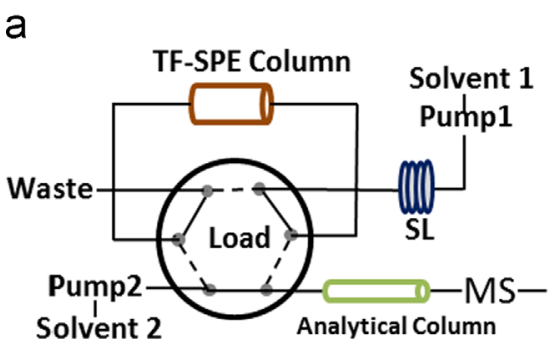

b

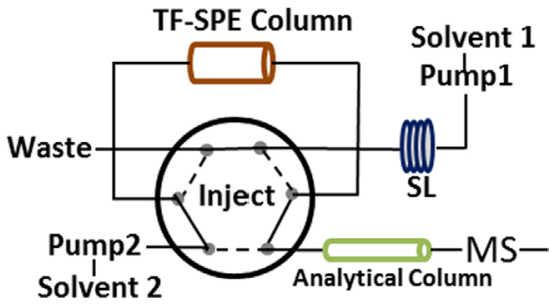

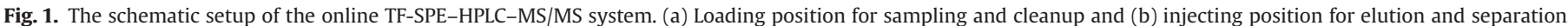
SL: sample loop. 
component of the mobile phase to improve the efficiency of protonation. The most intensive pseudo-molecular ion $[\mathrm{M}+\mathrm{H}]^{+}$ in positive ion mode and two most intensive related product ions are listed in Table 1. One product ion was used for quantification and the other for confirmation. Multiple reaction monitoring (MRM) scanning in the positive mode was performed to identify the ion pairs.

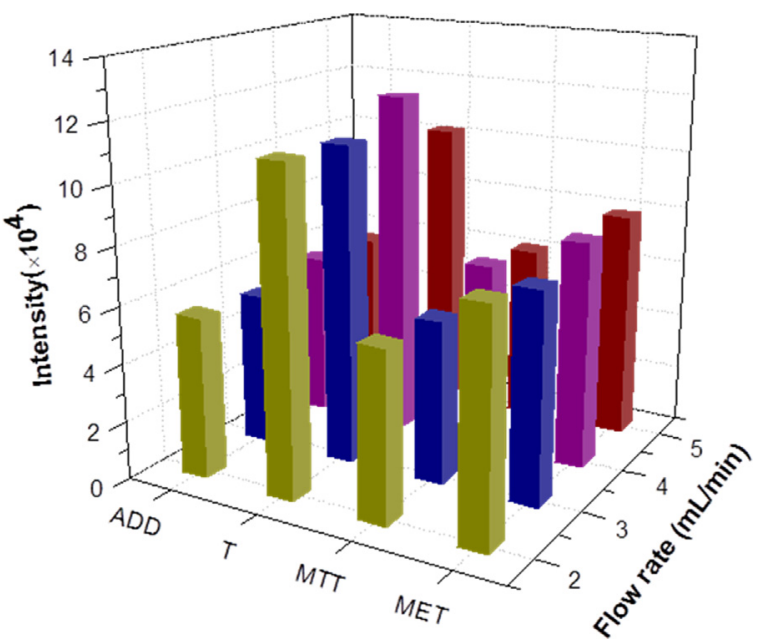

Fig. 3. Optimization of sample flow rates. The spiked $20 \mathrm{ng} / \mathrm{mL}$ standard solutions was run in replicate $(n=5)$. Sample volume $100 \mu \mathrm{L}$. Online SPE column: Turboflow C18-P column $(60 \mu \mathrm{m}, 1.0 \times 50 \mathrm{~mm})$. Sample cleanup with $5 \%$ ACN $(\mathrm{v} / \mathrm{v})$ for $1 \mathrm{~min}$.

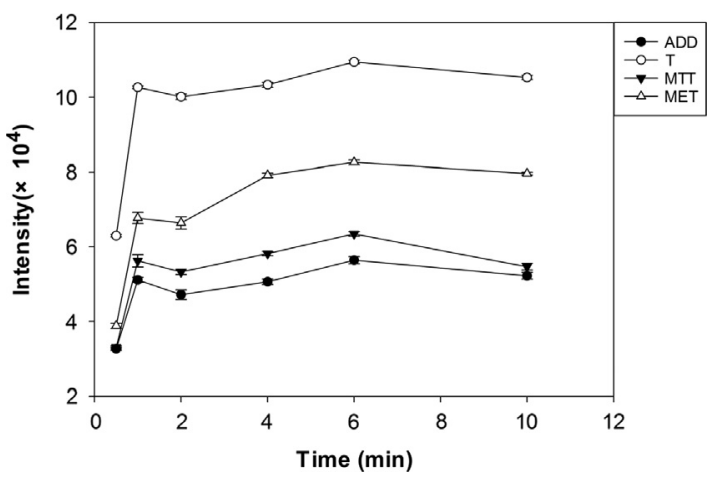

Fig. 4. Optimization of elution times. The spiked $20 \mathrm{ng} / \mathrm{mL}$ standard solutions was run in replicate $(n=5)$. Sample volume $100 \mu \mathrm{L}$. Online SPE column: Turboflow C18-P column $(60 \mu \mathrm{m}, 1.0 \times 50 \mathrm{~mm})$. Sample cleanup with $5 \%$ ACN $(v / v)$ for $1 \mathrm{~min}$. Sample loading flow rate $4 \mathrm{~mL} / \mathrm{min}$.

\subsection{Optimization of the online TF-SPE-HPLC procedure}

Several related conditions of online TF-SPE-HPLC procedure, including HPLC parameters, selection of online SPE column, sample volume, sample loading flow rate, sample cleanup and elution time, were carefully optimized.

HPLC method was firstly optimized to ensure the identification and quantification of all the analytes. The HPLC parameters were optimized including the selection of analytical column, mobile phase, the elution procedure and the flow rate of mobile phase. Firstly, the Acclaim C18 $(5 \mu \mathrm{m}, 4.6 \times 250 \mathrm{~mm})$ column and the Acclaim PA2 $(3 \mu \mathrm{m}, 3.0 \times 150 \mathrm{~mm})$ column were compared. Better peak shapes of the four analytes were obtained when using the Acclaim PA2 column. An acetonitrile/water mixture was more efficient than methanol/water mixture as the mobile phase. Considering potential organic impurities in sample may transfer from online SPE column to analytical column, low organic composition (40\% ACN) was used for original elution. After transition, isocratic elution from $40 \%$ ACN to $95 \%$ ACN in 5 min was tested, but the peaks of the four analytes were overlapped. In order to obtain a baseline separation, a gradient elution was then used. Satisfied separation was obtained when the composition of ACN increased from $40 \%$ to $60 \%$ in $5 \mathrm{~min}$ and further increased to $95 \%$ in $8 \mathrm{~min}$. Then, the organic component increased to $100 \%(\mathrm{v} / \mathrm{v})$ in $2 \mathrm{~min}$ and kept for 5 min to ensure complete elution of the residual analytes. Two flow rates of $0.4 \mathrm{~mL} / \mathrm{min}$ and $0.2 \mathrm{~mL} / \mathrm{min}$ were compared. When $0.4 \mathrm{~mL} / \mathrm{min}$ was used, the repeatability of the method was poor. The final gradient elution and optimized parameters are shown in Table 2.

Two types of commercial turboflow SPE columns were compared, including silica-based Turboflow C18-P $(60 \mu \mathrm{m}, 1.0 \times$ $50 \mathrm{~mm}$, Thermo Scientific) and polymeric Turboflow Cyclone-P ( $60 \mu \mathrm{m}, 1.0 \times 50 \mathrm{~mm}$, Thermo Scientific). The turboflow columns combine the features of size exclusion chromatography and reversed phase chromatography. The major characteristic is the large particles $(60 \mu \mathrm{m})$ of solid phase in column, which make them separate large matrix components from smaller molecules efficiently when the fluid in the column is turbulent. Therefore, endogenous macromolecules such as proteins as well as nonvolatile substances in urine may be excluded and have no time to diffuse into the pores of particles and generate physical and chemical reaction at a certain sample loading flow rate $[31,32]$. Smaller molecules both polar and nonpolar ones were absorbed into particles theoretically. In order to evaluate the extraction efficiencies of the two SPE columns, the peak areas of target compounds obtained from online analysis of standard solutions at $40 \mathrm{ng} / \mathrm{mL}$ in replicate $(n=5)$ were compared. Other parameters in this step included $100 \mu \mathrm{L}$ of sample volume, samples cleaned up with $5 \% \mathrm{ACN}(\mathrm{v} / \mathrm{v})$ for $1 \mathrm{~min}$, and sample loading flow rates of

Table 3

The linearity, reproducibility, LODs and spike recoveries for the four AAS.

\begin{tabular}{|c|c|c|c|c|c|c|c|c|c|c|c|c|}
\hline \multirow[t]{2}{*}{ Analytes } & \multirow{2}{*}{$\begin{array}{l}\text { Retention } \\
\text { time (min) }\end{array}$} & \multirow{2}{*}{$\begin{array}{l}\text { Calibration } \\
\text { curve }\end{array}$} & \multirow[t]{2}{*}{$R^{2}$} & \multirow{2}{*}{$\begin{array}{l}\text { Line range } \\
(\mathrm{ng} / \mathrm{mL})\end{array}$} & \multicolumn{2}{|c|}{$\operatorname{RSD}(\%, n=5)$} & \multirow{2}{*}{$\begin{array}{l}\text { IDL } \\
(\mathrm{pg})\end{array}$} & \multirow{2}{*}{$\begin{array}{l}\text { LOD } \\
(\mathrm{ng} / \mathrm{mL})\end{array}$} & \multicolumn{4}{|c|}{ Spike recovery $(\%) \pm S D, n g / m L$} \\
\hline & & & & & $\begin{array}{l}\text { Intra- } \\
\text { day }\end{array}$ & $\begin{array}{l}\text { Inter- } \\
\text { day }\end{array}$ & & & 0.05 & 0.5 & 1 & 10 \\
\hline ADD & 20.40 & $\begin{array}{l}Y=10472 \\
X-2593.5\end{array}$ & 0.9998 & $0.01-100$ & 11.0 & 10.4 & 2.0 & 0.002 & $150.5 \pm 10.8$ & $113.1 \pm 9.4$ & $130.6 \pm 15.9$ & $88.2 \pm 6.0$ \\
\hline $\mathrm{T}$ & 20.67 & $\begin{array}{l}Y=10434 \\
X+101.2\end{array}$ & 0.9996 & $0.01-100$ & 1.1 & 12.4 & 4.0 & 0.005 & $109.2 \pm 13.8$ & $90.2 \pm 15.4$ & $92.7 \pm 15.6$ & $117.8 \pm 11.4$ \\
\hline MTT & 21.59 & $\begin{array}{l}Y=8740.2 \\
X-534.61\end{array}$ & 0.9990 & $0.01-100$ & 5.1 & 7.5 & 2.0 & 0.002 & $87.6 \pm 20.3$ & $88.7 \pm 12.1$ & $105.3 \pm 15.7$ & $120.8 \pm 20.6$ \\
\hline MET & 21.88 & $\begin{array}{l}Y=6226.4 \\
X-1267.1\end{array}$ & 0.9999 & $0.01-100$ & 8.8 & 14.5 & 4.0 & 0.005 & $108.0 \pm 17.7$ & $78.6 \pm 13.3$ & $82.6 \pm 16.5$ & $102.3 \pm 15.3$ \\
\hline
\end{tabular}

IDL: instrumental detection limits. 
$2 \mathrm{~mL} / \mathrm{min}$. The extraction efficiencies for the four AAS with Turboflow C18-P and Turboflow Cyclone-P are shown in Fig. 2. The Turboflow C18-P column was eventually selected because it showed distinct advantage for all the analytes.

In order to evaluate the optimum injection volume, four sample volumes $(100 \mu \mathrm{L}, 200 \mu \mathrm{L}, 500 \mu \mathrm{L}$, and $1000 \mu \mathrm{L})$ were compared. The signals of the four AAS increased linearly with the increase of sample volume, nanogram per liter levels of the four AAS could be detected when the sample volume is $1.0 \mathrm{~mL}$. Considering the sample throughput, the injection volume was not further increased and a sample volume of $1.0 \mathrm{~mL}$ was confirmed.

Sample loading flow rate is a critical parameter for the online turbulent flow SPE procedure, which will determine the removal efficiency of matrix components and affect the preconcentration efficiency of the analytes. The loading flow rates ranging from $2 \mathrm{~mL} / \mathrm{min}$ to $5 \mathrm{~mL} / \mathrm{min}$ were tested. As shown in Fig. 3, there was no obvious increment or decrement of peak areas for the four target compounds. Slightly higher values were obtained under a flow rate of $4 \mathrm{~mL} / \mathrm{min}$. Therefore, a flow rate of $4 \mathrm{~mL} / \mathrm{min}$ was finally adopted in the analysis.

Although most of matrix components could be eliminated in the sample loading step, the cleanup step is still necessary for eliminating residual matrix components such as urea, uric acid, creatinine, ammonia and sulfate in urine after sample loading. An appropriate proportion of organic solvent could rinse them out. The mobile phase ( $5 \% \mathrm{ACN}$ at $4 \mathrm{~mL} / \mathrm{min}$ ) was kept as it was used in the sample loading step. When the cleanup time was increased from $1 \mathrm{~min}$ to $2 \mathrm{~min}$, the results showed that the responses of the four analytes decreased sharply. So $5 \%$ ACN for 1 min was used.

The optimum elution time was checked in order to ensure complete elution of analytes from Turboflow SPE column to analytical column. The elution times $0.5,1.0,2.0,4.0,6.0$, and $10.0 \mathrm{~min}$ were experimented. The responses of the four analytes decreased sharply when the elution time was shortened to $0.5 \mathrm{~min}$. On the contrary, no obvious increment of responses was found for all the target compounds when the elution time increased from $1.0 \mathrm{~min}$ to $10 \mathrm{~min}$. Although slightly higher responses were obtained when the elution time was at 4 min or 6 min (Fig. 4), the increment of the eluted matrix effect could not be justified in real sample analysis. Therefore, an elution time of 1.0 min was finally adopted.

\subsection{Quality control and method performance}

The proposed method was evaluated with special attention to its linearity, sensitivity, precision and accuracy. Seven-point standard curves were constructed by online analysis of spiked Milli-Q water with the analytes at concentration ranging from the LOQs to $100 \mathrm{ng} / \mathrm{mL}$. The linear regression coefficients $\left(r^{2}\right)$ for all standard curves of the analytes were higher than 0.9990, which was normally better than that achieved in offline analysis.

The LODs and LOQs were defined as the concentration for which the four analytes could be identified with a single-to-noise ratio greater than 3 and 10, respectively. The LOQs in Milli-Q water were $0.01 \mathrm{ng} / \mathrm{mL}$, which were ten times lower than the reported method by off-line SPE or online SPE analysis [15,19,26,33]. This was attributed to the combination of online SPE with large volume injection and high sensitive MS-MS spectrometry. The entire extract fraction was transferred onto the analytical column in online SPE protocols, instead of partial extraction as in offline procedure. Furthermore, HPLC-MS/MS (ESI) showed high sensitivity for these easily ionized compounds. All these allowed for determination of the four AAS in urine sample at nanogram per liter level. The values were much below general concern and might provide more information for clinical diagnosis and doping control.
The method precision were calculated as the intra-day and inter-day relative standard deviations (RSDs) of replicate analysis of $100 \mathrm{ng} / \mathrm{L}$ of standard solution under optimum conditions within $(n=5)$ and among $(n=5)$ days. The intra-day and inter-day RSDs ranged from $1.1 \%$ to $14.5 \%$. The satisfactory repeatability was obtained due to the minimum manipulation and less error sources

Table 4

The results for quantitation of spiked urine samples in replicate test $(n=5)$ before and after three freeze-thaw cycles.

\begin{tabular}{lccc}
\hline Analytes & $\begin{array}{l}\text { Spiked concentration } \\
(\mathrm{ng} / \mathrm{mL})\end{array}$ & $\begin{array}{l}\text { Before freeze-thaw } \\
\text { cycles }(\mathrm{ng} / \mathrm{mL})\end{array}$ & $\begin{array}{c}\text { After freeze-thaw } \\
\text { cycles }(\mathrm{ng} / \mathrm{mL})\end{array}$ \\
\hline \multirow{2}{*}{ ADD } & 1 & $1.5 \pm 0.2$ & $2.1 \pm 0.3$ \\
& 10 & $9.4 \pm 1.4$ & $11.5 \pm 2.0$ \\
& 40 & $42.5 \pm 3.2$ & $43.1 \pm 4.3$ \\
$\mathrm{~T}$ & 1 & $0.9 \pm 0.1$ & $0.6 \pm 0.1$ \\
& 10 & $11.6 \pm 1.4$ & $8.5 \pm 0.9$ \\
MTT & 40 & $40.3 \pm 2.0$ & $41.5 \pm 2.5$ \\
& 1 & $1.2 \pm 0.2$ & $0.9 \pm 0.2$ \\
& 10 & $12.3 \pm 1.1$ & $9.2 \pm 1.3$ \\
MET & 1 & $41.2 \pm 2.5$ & $39.5 \pm 3.6$ \\
& 10 & $0.9 \pm 0.2$ & $0.5 \pm 0.1$ \\
& 40 & $10.7 \pm 1.8$ & $9.4 \pm 1.0$ \\
& 10 & $40.5 \pm 2.4$ & $40.1 \pm 2.8$ \\
\hline
\end{tabular}

Table 5

Analytical results of the four AAS in urine samples (ng/L).

\begin{tabular}{|c|c|c|c|c|}
\hline Samples & ADD & $\mathrm{T}$ & MTT & MET \\
\hline \multicolumn{5}{|l|}{ Athletes } \\
\hline Sample 1 & 1121.6 & 204.1 & ND & ND \\
\hline Sample 2 & 1865.4 & 416.0 & ND & ND \\
\hline Sample 3 & 1643.1 & 522.4 & ND & ND \\
\hline Sample 4 & 1217.3 & 270.2 & ND & ND \\
\hline Sample 5 & 2707.2 & 808.4 & ND & ND \\
\hline Sample 6 & 878.7 & 185.4 & ND & ND \\
\hline Sample 7 & 1144.2 & 210.8 & ND & ND \\
\hline Sample 8 & 1396.7 & 206.7 & ND & ND \\
\hline Sample 9 & 742.2 & 175.7 & ND & ND \\
\hline Sample 10 & 1231.8 & 240.1 & ND & ND \\
\hline Sample 11 & 1295.1 & 274.3 & ND & ND \\
\hline Sample 12 & 1611.6 & 308.9 & ND & ND \\
\hline Sample 13 & 493.9 & 101.4 & ND & ND \\
\hline Sample 14 & 870.3 & 181.8 & ND & ND \\
\hline Sample 15 & 1044.8 & 285.6 & ND & ND \\
\hline Sample 16 & 373.3 & 55.5 & ND & ND \\
\hline Sample 17 & 1183.3 & 206.5 & ND & ND \\
\hline Sample 18 & 1321.7 & 314.3 & ND & ND \\
\hline Sample 19 & 507.5 & 97.6 & ND & ND \\
\hline Sample 20 & 537.5 & 104.1 & ND & ND \\
\hline Sample 21 & 439.6 & 80.9 & ND & ND \\
\hline Sample 22 & 448.2 & 80.3 & ND & ND \\
\hline Sample 23 & 421.7 & 63.6 & ND & ND \\
\hline Sample 24 & 412.6 & 66.7 & ND & ND \\
\hline \multicolumn{5}{|l|}{ Patients } \\
\hline Sample 1 & 653.0 & 89.9 & ND & ND \\
\hline Sample 2 & 505.0 & 70.0 & ND & ND \\
\hline Sample 3 & 699.6 & ND & ND & ND \\
\hline Sample 4 & 467.2 & 55.2 & ND & ND \\
\hline Sample 5 & 434.9 & 48.1 & ND & ND \\
\hline Sample 6 & 379.6 & ND & ND & ND \\
\hline Sample 7 & 378.1 & ND & ND & ND \\
\hline Sample 8 & 525.9 & 61.6 & ND & ND \\
\hline Sample 9 & 393.8 & 47.0 & ND & ND \\
\hline Sample 10 & 474.0 & 59.4 & ND & ND \\
\hline Sample 11 & 398.0 & 52.5 & ND & ND \\
\hline Sample 12 & 459.4 & 51.2 & ND & ND \\
\hline Sample 13 & 493.2 & 62.2 & ND & ND \\
\hline Sample 14 & 399.2 & ND & ND & ND \\
\hline Sample 15 & 461.3 & 59.1 & ND & ND \\
\hline
\end{tabular}

"ND" stands for "below limits of detection". 
of the fully automatic online SPE analysis. The detailed data are shown in Table 3. The method accuracy was determined by comparing the mean calculated concentration to the spiked target concentration of the urine sample at four different concentration levels $(0.05,0.5,1$ and $10 \mathrm{ng} / \mathrm{mL})$.

Sample stability was evaluated by analyzing of spiked samples at three concentration levels after repeated freeze-thaw cycles. Control samples were analyzed without thawing at room temperature $\left(22^{\circ} \mathrm{C}\right)$ and compared to the same samples which were frozen at $-20{ }^{\circ} \mathrm{C}$ and thawed three times in a week. Table 4 summarizes the results for urine sample proceed freeze-thaw cycles at three concentrations of $1 \mathrm{ng} / \mathrm{mL}, 10 \mathrm{ng} / \mathrm{mL}$ and $40 \mathrm{ng} / \mathrm{mL}$. There was no distinct effect on the quantitation of samples at $10 \mathrm{ng} / \mathrm{mL}$ and $40 \mathrm{ng} / \mathrm{mL}$. Relatively significant effect was found at $1 \mathrm{ng} / \mathrm{mL}$ compared to that of $10 \mathrm{ng} / \mathrm{mL}$ and $40 \mathrm{ng} / \mathrm{mL}$. Therefore, the fresh samples were recommended to determine as soon as possible after collection.

\subsection{Analysis of urine samples}

The proposed method was applied in the analysis of 39 urine samples as a part of the validation procedure. The urine samples were collected from 24 male athletes and 15 patients of prostate cancer in a hospital. The analytical results are shown in Table 5. Androstenedione were detected in all samples with the concentration in the range 373.3-2707.2 ng/L. Testosterone was detectable in most of the samples except four samples collected from patients. Exogenous methyltestosterone and methenolone, which were strictly prohibited in competition and prescribed as required in clinical treatment, were not detectable in all samples.

Matrix spiked recoveries were studied by analyzing urine samples of healthy adult spiked with the analytes at $0.05 \mathrm{ng} / \mathrm{mL}$, $0.5 \mathrm{ng} / \mathrm{mL}, 1 \mathrm{ng} / \mathrm{mL}$ and $10 \mathrm{ng} / \mathrm{mL}$, respectively. Total ion chromatogram and MRM chromatograms (first transition) obtained from online TF-SPE-LC-MS/MS analysis of the four AAS spiked at $10 \mathrm{ng} /$ $\mathrm{L}$ in urine sample are shown in Fig. 5. Because the real samples may already contain testosterone and androstenedione, nonspiked matrix samples were also analyzed $(n=5)$ and the peak areas were afterwards subtracted. As shown in Table 3, the mean recoveries ranged from $78.6 \%$ to $120.8 \%$ for testosterone, methyltestosterone and methenolone in urine samples. The results indicated that there was no distinct matrix suppression or enhancement for these three compounds. For androstenedione, the recoveries were satisfied for the spiked concentrations of $0.5,1$, and $10 \mathrm{ng} / \mathrm{mL}$, although high recoveries (150.5\%) was found for spiked concentration of $0.05 \mathrm{ng} / \mathrm{mL}$. This was probably because the spiked concentration was close to LOQ, and two carbonyl groups in molecular structure were more affected than the other analytes with one carbonyl groups.

\section{Conclusion}

An automated and sensitive method was developed for simultaneous determination of testosterone, androstenedione, methyltestosterone and methenolone in urine samples with online TF-SPE-HPLC-MS/MS. The procedures of pretreatment and analysis were largely simplified and fully automated. The complicated matrix components of urine could be effectively eliminated under a high flow rate at $4 \mathrm{~mL} / \mathrm{min}$. Turboflow C18-P column was effective to eliminate matrix components and showed best extraction efficiency for the target compounds. High sensitivity was obtained with the combination of large volume injection and MSMS detection. The good linearity and reproducibility of the method satisfied the need for quantifying the four AAS in urine samples. The recoveries for the four analytes were satisfied except a high recovery (150.5\%) for androstenedione at the low spiked concentration close to LOQ. This still needs to be further optimized in the future work. This automatic, sensitive and practical method

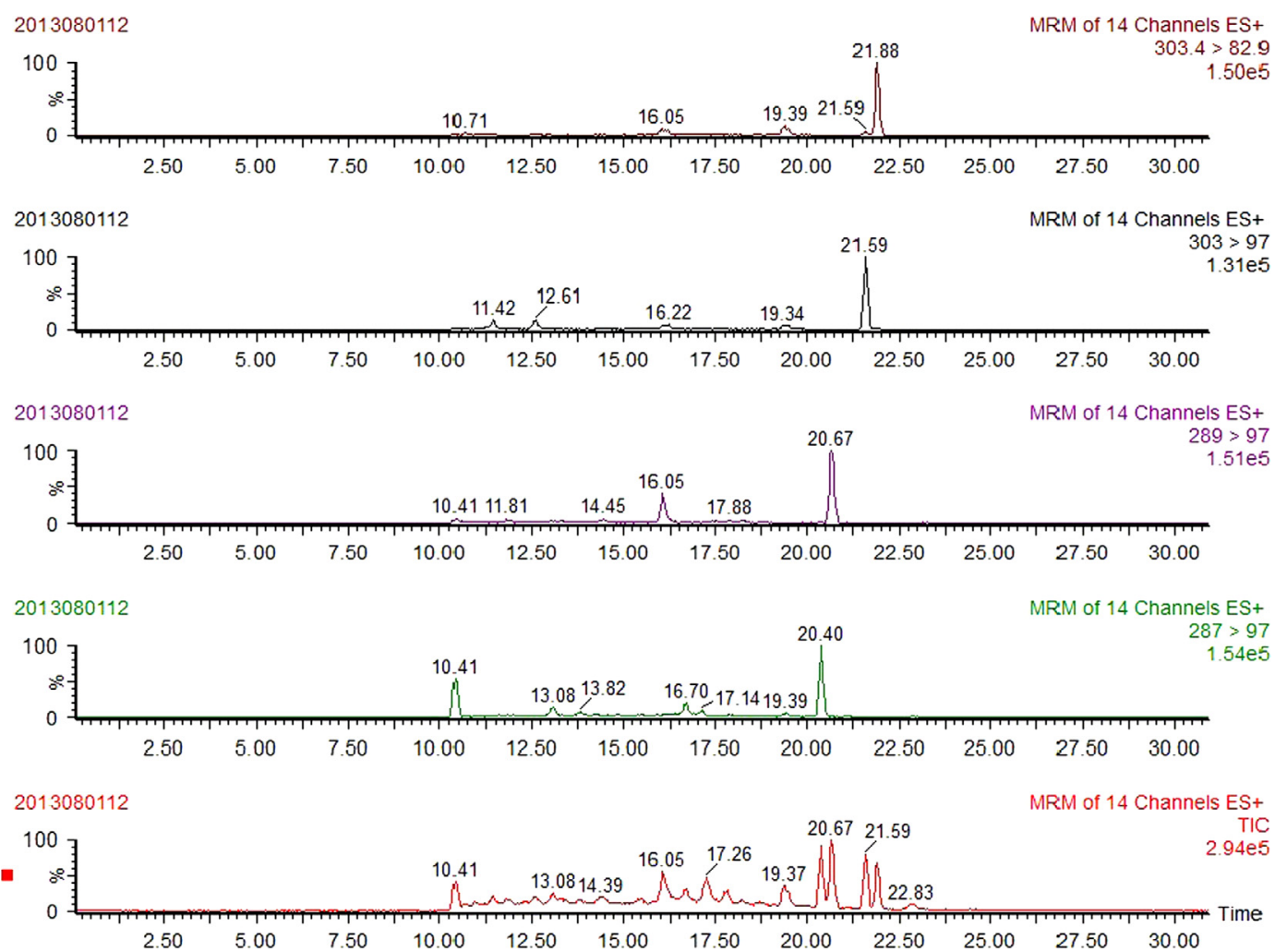

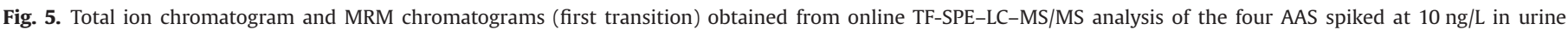
sample. 
provided an effective alternative way to fast determine these anabolic androgenic steroids in urine samples.

\section{Acknowledgment}

This work was supported by the National Natural Science Foundation of China (No. 21377155), the Ministry of Science and Technology of the People's Republic of China (No. 2012BAK25B01) and the Chinese Academy of Sciences (No. YSW2013A01).

\section{References}

[1] A.S. Clark, L.P. Henderson, Neurosci. Biobehav. Rev. 27 (2003) 413-436.

[2] A.G. Fragkaki, Y.S. Angelis, M. Koupparis, A. Tsantili-Kakoulidou, G. Kokotos, C. Georgakopoulos, Steroids 74 (2009) 172-197.

[3] J.C. Botelho, C. Shacklady, H.C. Cooper, S.S.C. Tai, K. Van Uytfanghe, L.M. Thienpont, H.W. Vesper, Clin. Chem. 59 (2013) 372-380.

[4] A.E. Kulle, F.G. Riepe, D. Melchior, O. Hiort, P.M. Holterhus, J. Clin. Endocrinol. Metab. 95 (2010) 2399-2409.

[5] I. Zofkova, K. Zajickova, M. Hill, J. Endocrinol. Invest. 27 (2004) 442-444.

[6] W. Schanzer, Clin. Chem. 42 (1996) 1001-1020.

[7] N.A. Evans, Am. J. Sports Med. 32 (2004) 534-542.

[8] C.C. Liu, S.P. Huang, Y.C. Lee, C.J. Wang, W.J. Wu, C.H. Huang, C.N. Huang, J. Sex. Med. 10 (2013) 234-234.

[9] T. Imamoto, T. Utsumi, T. Sazuka, M. Yanagisawa, M. Yano, S. Sakamoto, K. Kawamura, N. Kamiya, N. Nihei, H. Suzuki, T. Ichikawa, J. Sex. Med. 10 (2013) 206-206.

[10] L. Mearini, A. Zucchi, E. Nunzi, T. Villirillo, V. Bini, M. Porena, World J. Urol. 31 (2013) 247-252.

[11] R.B. Ness, J.D. Albano, A. McTiernan, J.A. Cauley, Arch. Intern. Med. 169 (2009) 41-46.

[12] A. Weltring, F.S. Schaebs, S.E. Perry, T. Deschner, Physiol. Behav. 105 (2012) 510-521.
[13] J. Marcos, J.A. Pascual, J. Barbosa, J. Segura, J. Microcolumn Sep. 12 (2000) $623-629$.

[14] K. Homma, T. Hasegawa, T. Nagai, M. Adachi, R. Horikawa, I. Fujiwara, T. Tajima, R. Takeda, M. Fukami, T. Ogata, J. Clin. Endocrinol. Metab. 91 (2006) 2643-2649.

[15] L. Konieczna, A. Plenis, I. Oledzka, P. Kowalski, T. Baczek, Talanta 83 (2011) $804-814$.

[16] IOC (International Olympic Committee) News Official Release, 2012. See 〈http://www.olympic.org/news/ioc-withdraws-gold-medal-from-shot-put-ath lete-nadzeya-ostapchuk/172684〉 (accessed 27.12.13).

[17] NBA News Official Release, 2013. See 〈http://www.nba.com/2013/news/02/13 turkoglu-suspended-official-release/index.html $\rangle$ (accessed 27.12.13).

[18] T. Soeborg, H. Frederiksen, P. Fruekilde, T.H. Johannsen, A. Juul, A.M. Andersson, Clin. Chim. Acta 419 (2013) 95-101.

[19] P. Hoffmann, M.F. Hartmann, T. Remer, K.P. Zimmer, S.A. Wudy, Steroids 75 (2010) 1067-1074

[20] X. de la Torre, C. Colamonici, D. Curcio, F. Molaioni, F. Botre, Anal. Chim. Acta 756 (2012) 23-29.

[21] E. Erdogan, M.M. Kushnir, B. Yue, T.L. Blamires, W.L. Roberts, A.W. Meikle A.L. Rockwood, Clin. Chem. 55 (2009) 184-184.

[22] L.M. Gallagher, L.J. Owen, B.G. Keevil, Ann. Clin. Biochem. 44 (2007) 48-56.

[23] J.P. Danaceau, M.S. Morrison, M.H. Slawson, J. Mass Spectrom. 43 (2008) 993-1000.

[24] M. Rauh, J. Steroid Biochem. 121 (2010) 520-527.

[25] S. Mirmandieh, A. Mardihallaj, Z. Hashemian, J. Razavizadeh, H. Ghaziaskar, T. Khayamian, J. Sep. Sci. 34 (2011) 107-112.

[26] B.T.S. Bui, F. Merlier, K. Haupt, Anal. Chem. 82 (2010) 4420-4427.

[27] Y. Zhan, F.M. Musteata, F.A. Basset, J. Pawliszyn, Bioanalysis 3 (2011) 23-30.

[28] R.C.P. Sequeiros, N.R. Neng, F.C.M. Portugal, M.L. Pinto, J. Pires, J.M.F. Nogueira, J. Chromatogr. Sci. 49 (2011) 297-302.

[29] M. Rauh, M. Groschl, W. Rascher, H.G. Dorr, Steroids 71 (2006) 450-458.

[30] W.A. Salameh, M.M. Redor-Goldman, N.J. Clarke, R.E. Reitz, M.P. Caulfield Steroids 75 (2010) 169-175.

[31] R. Lopez-Serna, M. Petrovic, D. Barcelo, J. Chromatogr. A 1252 (2012) 115-129.

[32] L. Couchman, Biomed. Chromatogr. 26 (2012) 892-905.

[33] G. Kaur-Atwal, J.C. Reynolds, C. Mussell, E. Champarnaud, T.W. Knapman, A.E. Ashcroft, G. O'Connor, S.D.R. Christie, C.S. Creaser, Analyst 136 (2011) 3911-3916. 